\title{
Inhibition of superoxide production in human neutrophils by combinations of heparin and thrombolytic agents
}

\author{
Klaris Riesenberg, Francisc Schlaeffer, Amos Katz, Rachel Levy
}

\begin{abstract}
Objective-To investigate the effect of heparin and thrombolytic agents on superoxide generation by human neutrophils, as inhibition of superoxide production may have a role in reducing ischaemia and reperfusion injury.

Methods-Neutrophil superoxide production stimulated by phorbol myristate acetate (PMA), opsonised zymosan, or formyl methionyl leucyl phenylalanine (FMLP) was measured as the superoxide dismutase inhibitable reduction of acetyl ferricytochrome $c$ by a microtitre plate technique.

Results-Heparin, at concentrations of 0.5-500 U/ml, caused a gradual inhibition of superoxide production stimulated by PMA, opsonised zymosan, or FMLP. Tissue plasminogen activator was more potent than heparin in inhibiting superoxide production induced by opsonised zymosan or FMLP, but it did not affect the activity stimulated by PMA. Streptokinase or urokinase had no effect on superoxide production. When heparin was used in combination with tissue plasminogen activator, streptokinase, or urokinase at their therapeutic concentrations there was a significant inhibition of superoxide generation $(70 \%, 30 \%$, and $25 \%$, respectively). The therapeutic concentrations of tissue plasminogen activator alone caused a reduction of $40 \%$ of neutrophil superoxide production. When tissue plasminogen activator and streptokinase were both added to neutrophils, however, a synergistic inhibition of $\mathbf{8 0 \%}$ was achieved.

Conclusions-The inhibition of super oxide generation by these drug combinations may explain the limited inflammatory response and reduction of reperfusion injury observed in patients receiving thrombolytic treatment.
\end{abstract}

\section{(Br Heart f 1995;73:14-19)}

Keywords: superoxide production, neutrophils, heparin, thrombolytic agents.

The fundamental assumption underlying the current thrombolytic treatment of acute myocardial infarction is that the early restoration of myocardial blood flow arrests the progression of myocardial cell death, permitting the ultimate functional recovery of reversibly injured myocardium. Experimental and clinical studies have indicated that reperfusion of myocardium immediately after the onset of ischaemia can reduce infarct size and improve mortality after acute coronary artery occlusion. ${ }^{1-3}$ Although reperfusion ends ischaemia, it can also cause further damage to jeopardised cells, a phenomenon which has been termed reperfusion injury.

The precise pathophysiology of cellular damage after extreme ischaemia and reperfusion has not been completely established. Several contributing factors have been suggested, including production of toxic oxygen free radicals, endothelial cell swelling, and damage leading to increased capillary permeability, intravascular platelet activation, and fibrin deposition. Endothelial swelling combined with platelet and fibrin accumulation may ultimately result in microvascular thrombosis, thus preventing reperfusion. These sequelae have been termed the no reflow phenomenon. ${ }^{4}$

Recent work has focused on the role of neutrophils in the development of ischaemia and reperfusion injury. Activated neutrophils are a potent source of oxygen derived free radicals, and experimental data suggest that they may be important in the pathogenesis of reperfusion injury. ${ }^{56}$ Oxygen radicals depress the contractile function of isolated papillary muscles, ventricular septae, and isolated hearts. ${ }^{7}$ Cardiac tissue exposed to free radicals developed swollen mitochondria, endothelial damage, and abnormal vascular permeability. ${ }^{8}$

The biochemical basis for the generation of superoxide in neutrophils is the enzymatic complex NADPH oxidase..$^{10}$ This enzyme is dormant in resting neutrophils and is capable of being activated by several stimuli. ${ }^{11}$ The enzyme is a multicomponent electron transport complex which includes a membrane bound $b$-type cytochrome (flavocytochrome $\left.b_{558}\right){ }^{12-13}$ The cytochrome incorporates the NADPH binding site and both the flavin and haeme electron transfer moieties. ${ }^{14}$ In addition, superoxide generating activity depends on the presence of three cytosolic oxidase proteins which have been characterised as $47 \mathrm{kDa}$ (p47), $67 \mathrm{kDa}$ (p67), and ras related GTP binding proteins. ${ }^{15-18}$

We investigated whether heparin and thrombolytic agents have an inhibitory effect on superoxide generation by human neutrophils. Such an effect may contribute to the prevention of reperfusion injury. 


\section{Materials and methods} REAGENTS

The reagents used were heparin (Leo Pharmaceutical Products, Ballerup, Denmark); lyophilised streptokinase (Streptase, Behringwerke, Marburg, Germany); urokinase (Ukidan, Laboratoires Sero Aubonne, Switzerland); and tissue plasminogen activator produced by recombinant DNA technology (Activase, Genentech, San Francisco, California).

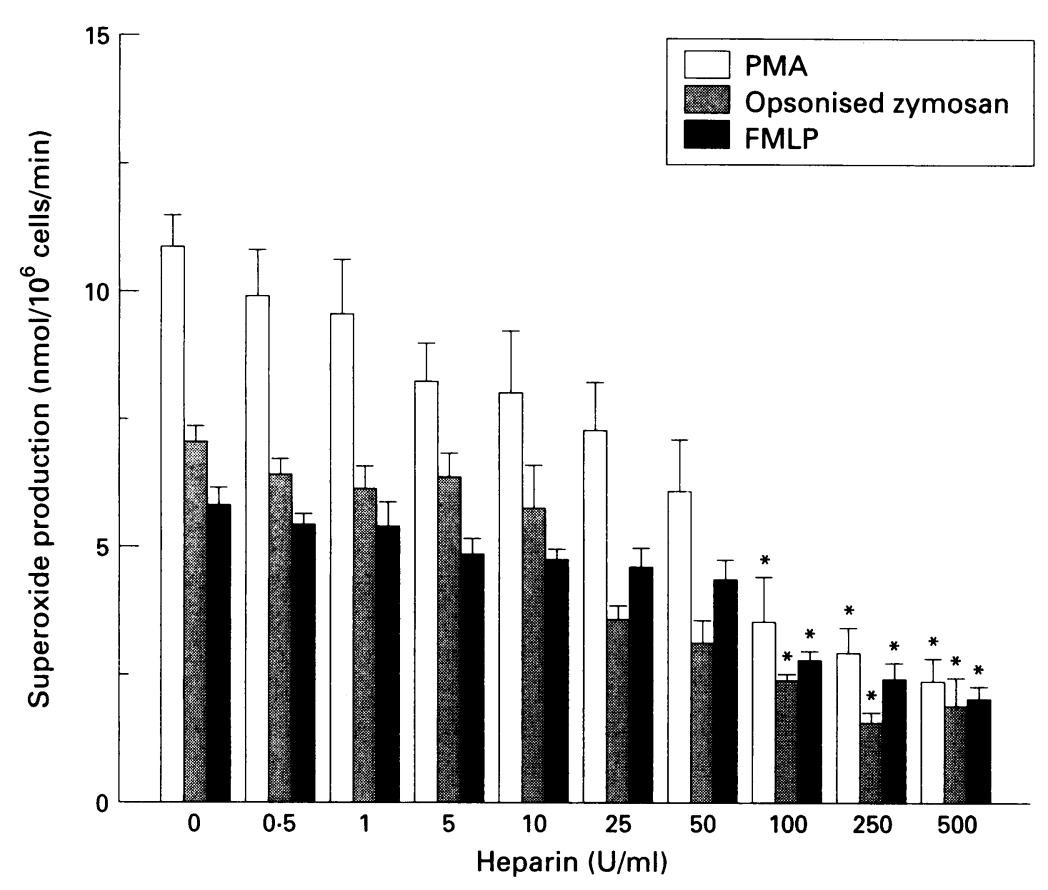

Figure 1 Effect of heparin on superoxide generation in stimulated human neutrophils. Results are means (SE) from five different experiments, each performed in duplicate. ${ }^{\star} P<0.001$ for inhibitory effect of heparin.

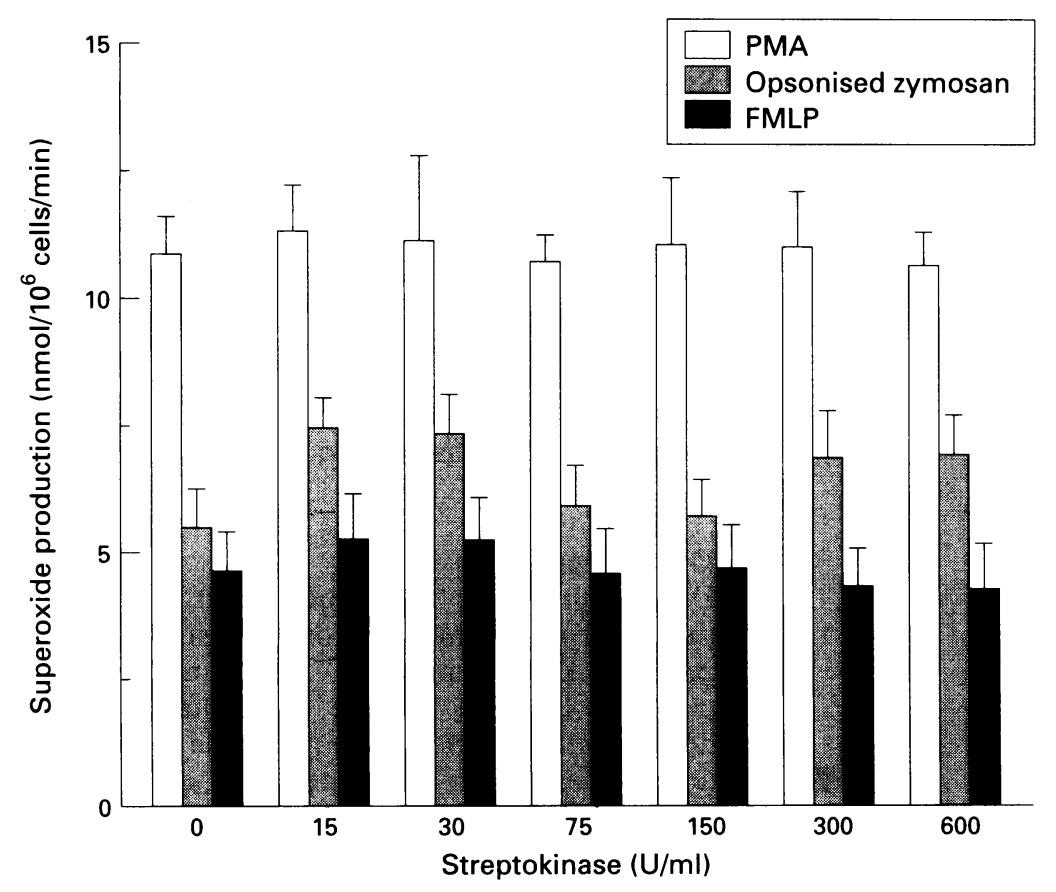

Figure 2 Effect of streptokinase on superoxide generation in stimulated human neutrophils. Results are means (SE) from five different experiments, each performed in duplicate.
ISOLATION OF NEUTROPHILS

Neutrophils were separated by Ficoll/ Hypaque centrifugation, dextran sedimentation, and hypotonic lysis of erythrocytes. ${ }^{19}$

\section{MEASUREMENT OF SUPEROXIDE ANION}

The production of superoxide anion $\left(\mathrm{O}_{2}^{-1}\right)$ by intact cells was measured as the superoxide dismutase inhibitable reduction of ferricytochrome $\mathrm{c}$ by a microtitre plate technique. ${ }^{20}$ Cells were suspended $\left(5 \times 10^{5}\right.$ cells/well $)$ in Hank's balanced salts solution $(100 \mu \mathrm{l})$ containing $150 \mathrm{mmol} / \mathrm{l}$ acetyl ferricytochrome c. Neutrophils were stimulated by the addition of $50 \mathrm{mg} / \mathrm{l}$ phorbol myristate acetate (PMA), $1 \mathrm{~g} / 1$ opsonised zymosan, or $100 \mathrm{nmol} / \mathrm{l}$ formyl methionyl leucyl phenylalanine (FMLP) and the reduction of acetyl ferricytochrome $c$ was followed by the change of absorbance at 550 nm every five minutes on a Thermomax microplate reader (Molecular Devices, Melno Park, California). The maximal rates of superoxide generation were determined using the extinction coefficient $\mathrm{E}_{550}=21 \mathrm{mM}^{-1} \mathrm{~cm}^{-1}$.

Addition of each of the drugs to a cell free assay system, performed as described in our previous study, ${ }^{20}$ did not affect superoxide generation measured by cytochrome $\mathrm{c}$ reduction.

\section{ANALYSIS OF DATA}

The differences in means were analysed by Student's $t$ test. The plots were drawn as least squares regression lines and tested by analysis of variance.

\section{Results}

The effect of both the anticoagulant (heparin) and the thrombolytic drugs (streptokinase, urokinase, and tissue plasminogen activator) on superoxide production in human neutrophils stimulated by PMA, opsonised zymosan, or FMLP is shown in this study. The drugs were added to the neutrophils before the addition of the stimuli. Preincubation with the drugs for different times, ranging from five minutes to one hour before the reaction, did not change the results. Heparin, in a range of $0.5-500 \mathrm{U} / \mathrm{ml}$, caused a gradual inhibition of superoxide production stimulated by any of the three stimuli (figure 1). The inhibition could be detected at $25 \mathrm{U} / \mathrm{ml}$ and higher. At $100 \mathrm{U} / \mathrm{ml}$ there was a significant inhibition of superoxide production $(P<0.001)$. There was no inhibition of activity at the concentration of heparin in plasma either after a continuous drip (0.1-1 $\mathrm{U} / \mathrm{ml}$ ) or after a bolus intravenous infusion $(5-10 \mathrm{U} / \mathrm{ml}){ }^{19}$

Streptokinase in the range of $15-600 \mathrm{U} / \mathrm{ml}$ (figure 2) and urokinase in the range of $10-5000 \mathrm{U} / \mathrm{ml}$ (figure 3) had no effect on superoxide production induced by any of the stimuli. The effect of tissue plasminogen activator in the range of $0 \cdot 1-100 \mathrm{mg} / \mathrm{l}$ on superoxide production is shown in figure 4 . There was a gradual and significant inhibition of superoxide generation in neutrophils stimulated by opsonised zymosan or FMLP. The 
concentration of tissue plasminogen activator (from $0.5 \mathrm{mg} / \mathrm{l}$ ), which caused a significant reduction of the activity, was in the range of its concentration in plasma during therapeutic infusions $(0 \cdot 3-3 \mathrm{mg} / \mathrm{l}) .{ }^{19}$ Superoxide production stimulated by PMA was not affected by tissue plasminogen activator in this concentration range. Since the different drugs are often

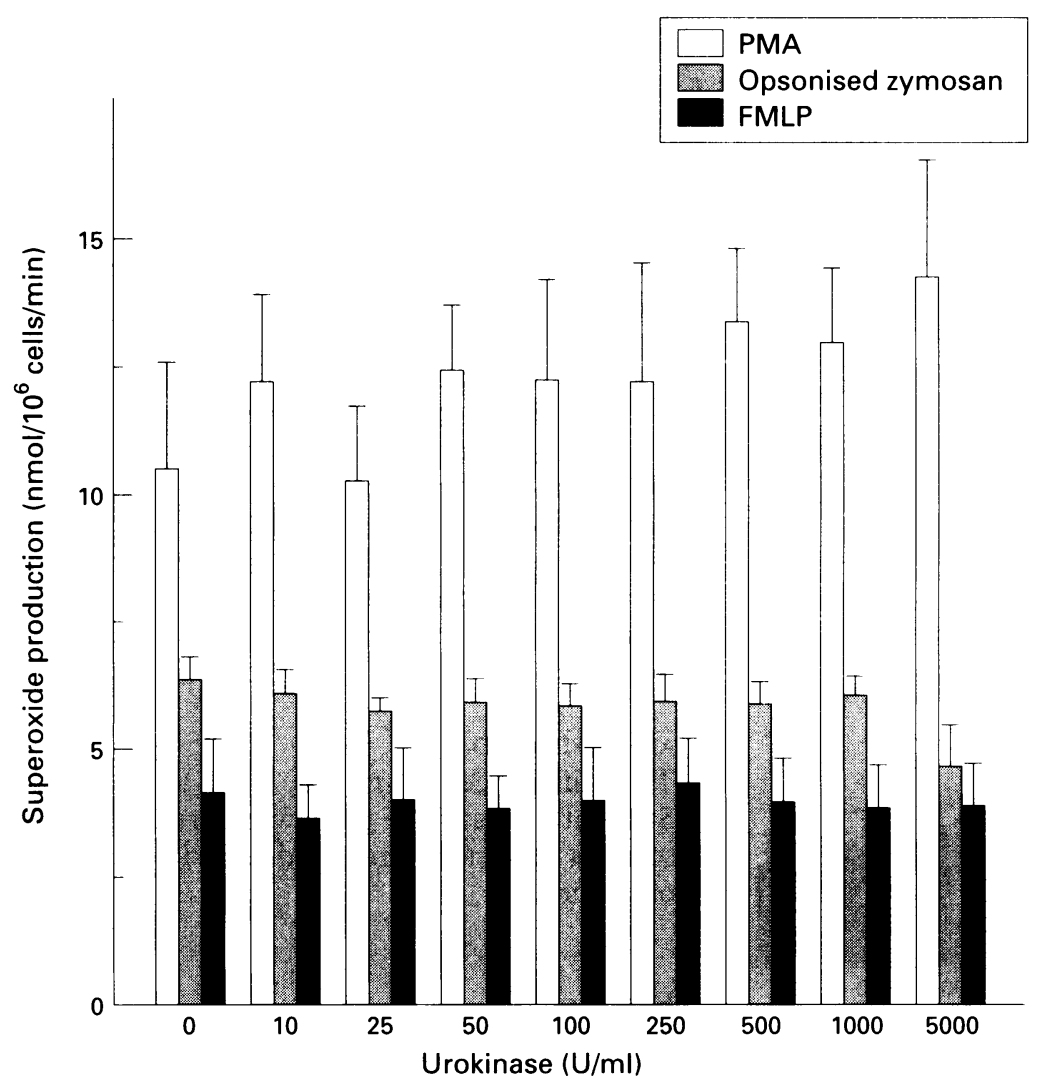

Figure 3 Effect of urokinase on superoxide generation in stimulated human neutrophils. Results are means (SE) from five different experiments, each performed in duplicate.

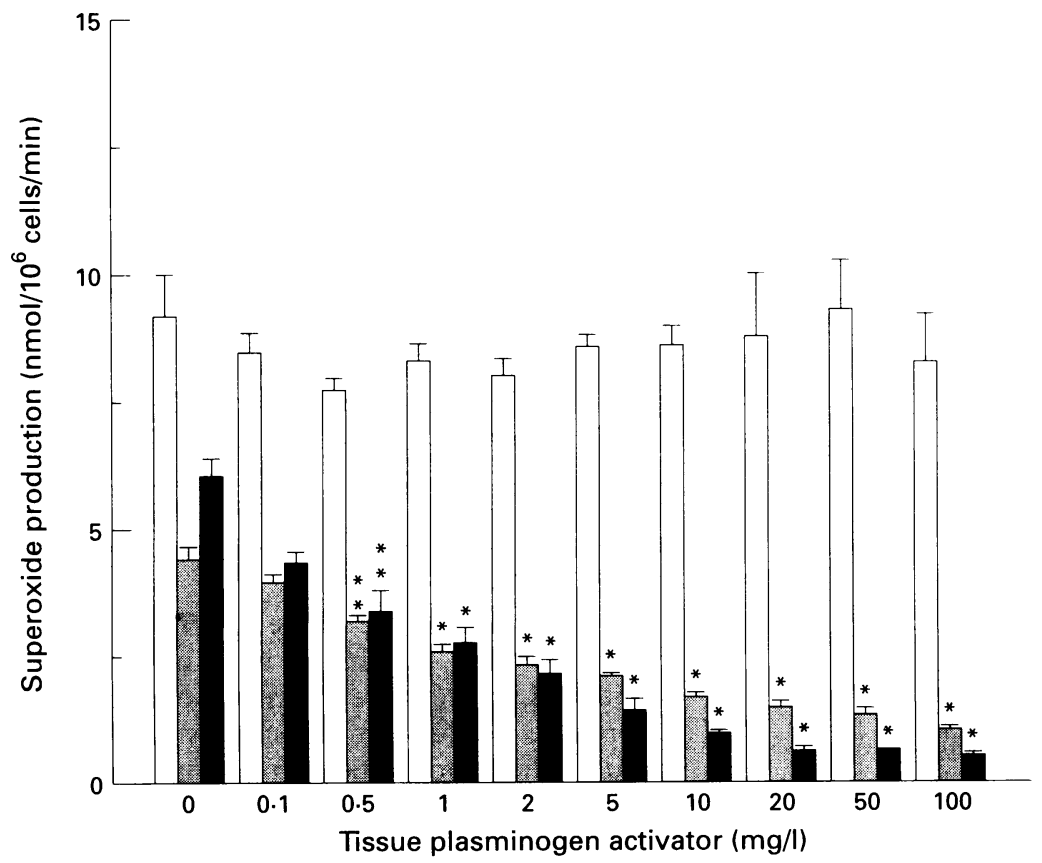

Figure 4 Effect of tissue plasminogen activator on superoxide generation in stimulated human neutrophils. Results are means (SE) from five different experiments, each performed in duplicate. ${ }^{\star} P<0.001,{ }^{\star} P<0.01$ for difference from control value. used simultaneously, the effect of various combinations of these drugs on the production of superoxide by neutrophils was studied. Figure 5 shows the effect of the combinations of heparin and streptokinase or heparin and urokinase on superoxide production. When heparin $10 \mathrm{U} / \mathrm{ml}$, a therapeutic dose that alone did not affect the generation of superoxide, was given with streptokinase (figure $5 \mathrm{~A}$ ) or with urokinase (figure $5 \mathrm{~B}$ ), both of which did not inhibit superoxide production, there was a marked and significant inhibition of activity. The maximal inhibition was achieved at therapeutic concentrations of streptokinase $(75 \mathrm{U} / \mathrm{ml})$ or urokinase $(10$ $\mathrm{U} / \mathrm{ml}) .^{21} \mathrm{~A}$ higher concentration of heparin $(100 \mathrm{U} / \mathrm{ml})$ was more efficient in inhibiting the activity when given together with streptokinase or urokinase.

Figure 6 shows the effect of heparin in combination with tissue plasminogen activator on superoxide production stimulated by opsonised zymosan. Heparin in its therapeutic concentration $(10 \mathrm{U} / \mathrm{ml})$ caused a slight and insignificant inhibition of superoxide production stimulated by opsonised zymosan $(2 \cdot 8$ $(0.6) \mathrm{nmol} / 10^{6}$ cells/min compared with 3.45 $\mathrm{nmol} / 10^{6}$ cells $/ \mathrm{min}$ in the control). In the presence of tissue plasminogen activator (in two therapeutic concentrations, $0 \cdot 1$ and 2 $\mathrm{mg} / \mathrm{l}$ ) the activity stimulated by opsonised zymosan was $3.25(0.5)$ and $2(0.2) \mathrm{nmol} / 10^{6}$ cells/min, respectively. When the activity was measured in the presence of both heparin and tissue plasminogen activator there was an additional inhibition of activity $(2 \cdot 2(0 \cdot 2)$ or $1.3(0 \cdot 1) \mathrm{nmol} / 10^{6}$ cells $/ \mathrm{min}$ by $10 \mathrm{U} / \mathrm{ml}$ heparin and $0.1 \mu \mathrm{g} / \mathrm{ml}$ tissue plasminogen activator or $10 \mathrm{U} / \mathrm{ml}$ heparin and $2 \mathrm{mg} / \mathrm{l}$ tissue plasminogen activator, respectively). Similar results were obtained in neutrophils stimulated by FMLP.

Figure 7 shows the effect caused by the combinations of tissue plasminogen activator and streptokinase on superoxide production. Streptokinase did not affect activity stimulated by opsonised zymosan or FMLP. However, when tissue plasminogen activator at concentrations of $0.1 \mathrm{mg} / 1$ or $2 \mathrm{mg} / \mathrm{l}$, which by themselves caused partial inhibition, were added together with streptokinase a significant inhibition $(\mathrm{P}<0.005)$ was achieved. This inhibition was observed at a low and therapeutic concentration of streptokinase (75 $\mathrm{U} / \mathrm{ml}$ ) and did not change significantly as the dose of streptokinase was increased.

\section{Discussion}

Our results show the direct effect of three thrombolytic agents and of heparin on the generation of superoxide by human neutrophils. Heparin caused a gradual, dose dependent inhibition of superoxide production by neutrophils stimulated with any of the three agents used in the study. The inhibition of superoxide production could be observed at $25 \mathrm{U} / \mathrm{ml}$ heparin and higher, with significant inhibition $(P<0.001)$ at a concentration of $100 \mathrm{U} / \mathrm{ml}$. Heparin is a naturally occurring 


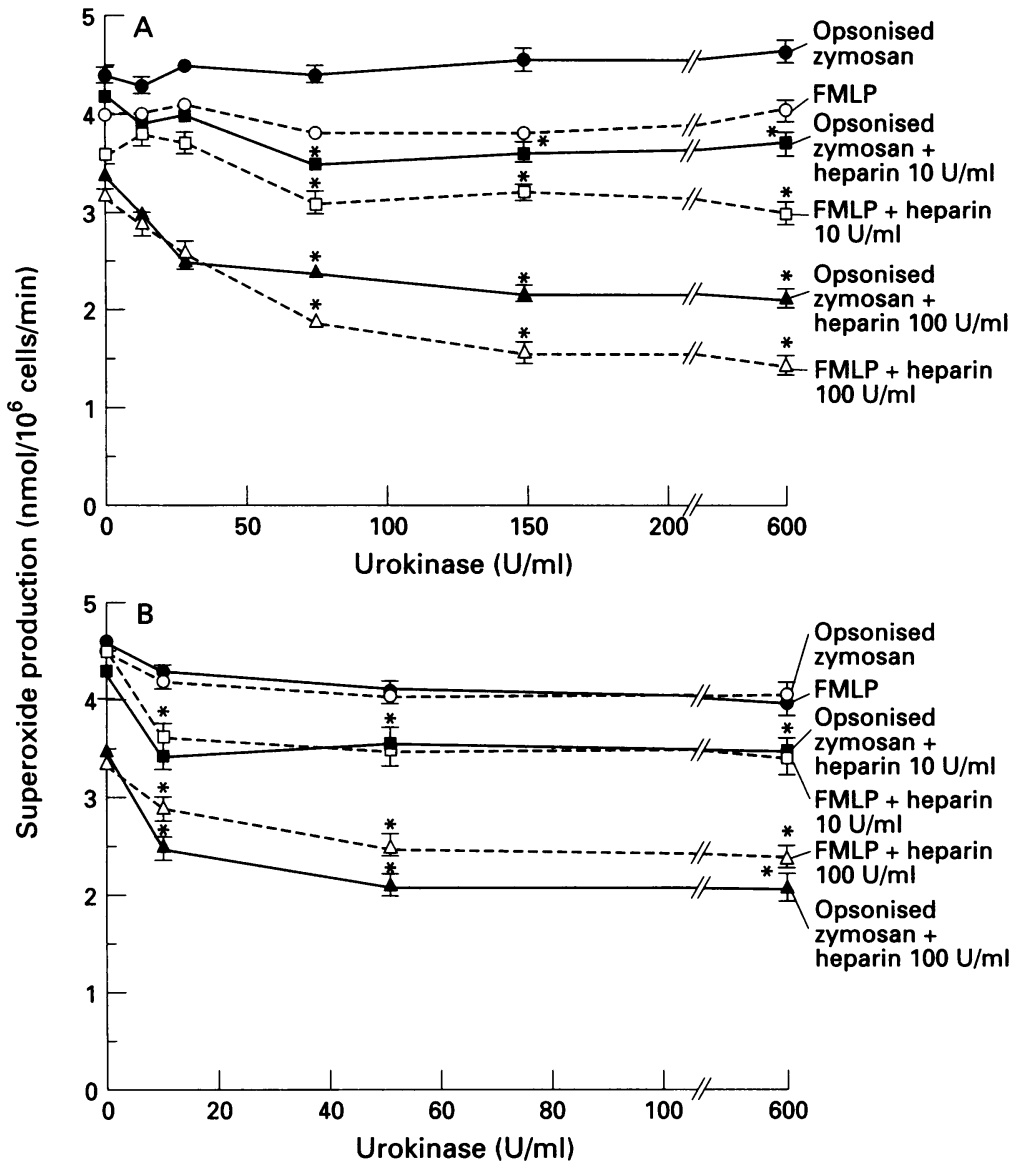

Figure 5 Combined effect of heparin and streptokinase $(A)$ or heparin and urokinase $(B)$ on stimulated superoxide production in human neutrophils. Results are means (SE) from four different experiments, each performed in duplicate. ${ }^{\star} P<0.001$ for difference from control value. mucopolysaccharide polymer that is concentrated in most cells, but it is also found in other tissues, including the endothelium. Clinically, heparin is used as an extremely potent anticoagulant that can reduce thrombin generation and fibrin formation by binding to and activating antithrombin III. Our results show that in addition to its anticoagulant effect, heparin also inhibits superoxide production by neutrophils.

The thrombolytic agent tissue plasminogen activator, which inhibits the generation of superoxide at its therapeutic concentration, was more potent than heparin in inhibiting superoxide production stimulated by opsonised zymosan or FMLP at the doses tested, but it did not affect the activity stimulated by PMA. Streptokinase, a protein produced by $\beta$ haemolytic streptococci, has no intrinsic enzymatic activity and forms a stable, non-covalent 1:1 complex with plasminogen. This produces a conformational change by which this complex activates additional plasminogen molecules to form free plasmin, thus causing fibrinolysis. Urokinase is a protease isolated from human renal tubular cell culture that has intrinsic proteolytic activity and can activate plasminogen directly. In contrast to heparin and tissue plasminogen activator, neither of these agents had any affect on superoxide production.

In accordance with our study, Freischlag et al have reported that urokinase did not affect superoxide production by neutrophils. ${ }^{22}$ In contrast to our study, which shows a dose dependent inhibition of heparin activity, they did not find any inhibition of activity by this drug. ${ }^{22}$ The contradictory results may be explained by the different conditions of the two studies. Freischlag et al preincubated the neutrophils with very high concentrations of urokinase, whereas we used urokinase at much lower concentrations. Also, they measured activity after washing off the drugs.

Although each drug by itself partially inhibited or did not affect superoxide production at all in our study, combinations of these drugs at their therapeutic concentrations resulted in a significant reduction in activity. These results are clinically important as the drugs are used simultaneously to cause reperfusion of myocardial infarcts. The most relevant results are for heparin in combination with one of the other agents as this is the most common treatment. Heparin by itself at its therapeutic concentration did not inhibit superoxide production, but when it was given in combination with each of the thrombolytic drugs there was a significant inhibition of superoxide generation. The combination of other drugs also resulted in significant inhibition of superoxide production. When tissue plasminogen activator and streptokinase were added together to neutrophils, a synergistic inhibition was achieved. The inhibition of superoxide generation by these drug combinations may play an important part in reducing the myocardial damage often caused by reperfusion.
This hypothesis is supported by several plasminogen activator on superoxide production stimulated by opsonised zymosan in human neutrophils. Results are means (SE) from five different experiments, each performed in triplicate. $C$, control ( neutrophils stimulated by opsonised zymosan, $\mathbb{Z}$ neutrophils stimulated by opsonised zymosan in presence of tissue plasminogen activator alone). ${ }^{\star} P<0.001,{ }^{\star}{ }^{*} P<0.01$ for difference from control value. 
studies in animals, which have shown that free radical scavengers are capable of reducing infarct size. ${ }^{2324}$ In addition, in experimental models of myocardial infarction in dogs, infarct size could be limited either by inhibiting neutrophil activation or by neutrophil depletion. The effect of thrombolytic treatment on neutrophils is contradictory in the literature. Streptokinase in acute myocardial infarction is associated with an abrupt reactive neutrophil response. ${ }^{25}$ However, other studies have shown, in accordance with our results, that thrombolysis by streptokinase and tissue plasminogen activator suppresses neutrophil activation and infiltration, suggesting that this treatment may even limit the inflammatory response and thus mitigate reperfusion injury. ${ }^{26} 27$ The improved mortality after thrombolysis and after $\beta$ blockade suggests that several factors can reduce acute ischaemic injury. Thus, the inhibitory effect of neutrophil superoxide production by combination of thrombolytic and anticoagulant agents shown in our study and the inhibition of neutrophil aggregation, ${ }^{28}$ chemotaxis, and phagocytosis ${ }^{29} 30$ suggest that these agents, in addition to their usual mechanisms of action, may reduce infarct size by inhibiting neutrophil activity. However, clinical studies are needed to confirm the potential therapeutic benefit of these drug combinations.

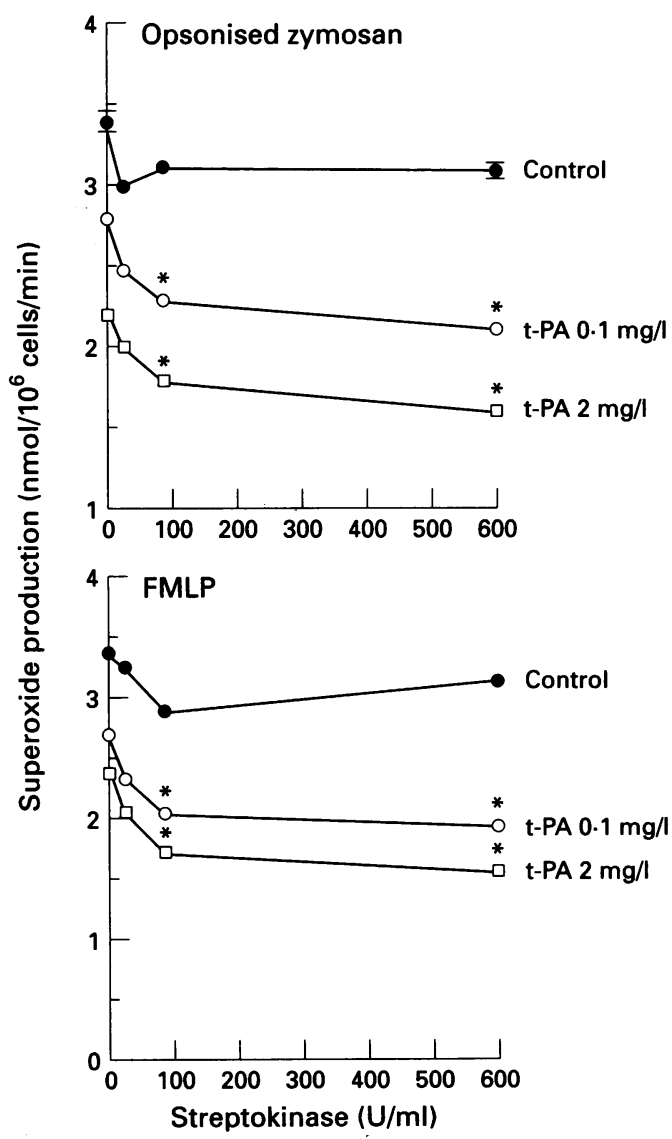

Figure 7 Combined effect of tissue plasminogen activator and streptokinase on superoxide production stimulated by opsonised zymosan or FMLP in human neutrophils. Results are from a representative experiment performed in Results are from a representative experiment performed in ${ }^{*} P<0.005$ for difference from control value.
The mechanism by which heparin or tissue plasminogen activator inhibits neutrophil NADPH oxidase to generate superoxide is not known. Our results suggest that they probably act through different mechanisms. Studies in whole cells provide considerable information about signal transduction pathways, suggesting that the oxidase may be activated by various stimuli through several pathways. $^{3132}$ When stimulated by PMA or diacylglycerol, NADPH oxidase is activated by protein kinase $\mathrm{C}$. $\mathrm{N}$-formyl peptide chemoattractants stimulate phosphoinositide hydrolysis and an increase in intracellular free calcium ions. Stimuli, such as opsonised particles, act through a calcium dependent pathway which is dependent on arachidonate. Since heparin inhibited the activity induced by the three stimuli, it probably affects intracellular signal transaction pathways that are shared by the different agonists, such as protein kinase $C$ activity. In contrast, tissue plasminogen activator inhibited the generation of superoxide induced by FMLP or opsonised zymosan and not by PMA, suggesting that tissue plasminogen activator interacts with neutrophil membranes and interferes with the receptors for this agonist. The inhibition of superoxide production by these drugs does not seem to be due to a scavenging effect as tissue plasminogen activator did not inhibit PMA stimulating activity (figure 4) and the addition of either heparin or tissue plasminogen activator did not affect NADPH oxidase activity in a cell free assay.

In conclusion, the significant inhibition of neutrophil superoxide by the anticoagulant and thrombolytic agents shown in this study may suggest that in addition to their effect in reducing reperfusion in myocardial infarction, they may also prevent reperfusion injury.

1 TIMI Study Group. The thrombolysis in myocardial infarction (TIMI) trial: phase 1 findings. $N \mathrm{Engl} \mathcal{F} \mathrm{Med}$ infarction (T1MI)

2 Guerci AD, Gerstenblith G, Brinker JA, Gottlieb SO, Weiss JL, Chandra NC, et al. A double-blind, placebocontrolled, randomized trial of tPA with subsequent rancontrolled, randomized trial of tPA with subsequent randomization to elective
Med 1988;37:1613-18.

3 International tPA/SK Mortality Trial Study Group. Inhospital mortality and clinical course of 20,891 patients with suspected acute myocardial infarction randomized between tissue plasminogen activator or streptokinase with or without heparin. Lancet 1990;336:71-5.

4 Flaherty JT, Weisfeldt ML. Reperfusion injury. Free Radic Biol Med 1988;5:409-19.

5 Lucchesi BR. Myocardial ischemia, reperfusion and free radical injury. Am f Cardiol 1990;65:14-23.

6 Mehta J, Dinerman J, Mehta P, Saldeen TGP, Lawson D, Donnelly WH, et al. Neutrophil function in ischemic heart disease. Circulation 1989;79:549-56.

7 Przyklenk $K$, Whittaker $P$, Kloner RA. In vivo infusion of oxygen free radical substates causes myocardial systolic, but not diastolic dysfunction. Am Heart f 1990;119. 807-15.

8 Otani $H$, Tanaka $H$, Inoue $T$, Umemoto $M$, Omoto $K$, Tanaka $\mathrm{K}$, et al. In vitro study on contribution of oxidative metabolism of isolated rabbit heart mitochondria to

myocardial reperfusion injury. Circ Res $1984 ; 55: 168-75$.
9 Malech HL, Gallin JI. Current concepts: immunology Malech HL, Gallin JI. Current concepts: immunology
neutrophils in human diseases. $N$ Engl $\mathcal{F}$ Med 1987;317: neutroph

10 Babior BM. Oxygen-dependent microbial killing by phagocytes - II. N Engl f Med 1978;298:721-6.

11 Rossi SJ: The $\mathrm{O}_{2}$-forming NADPH oxidase of the phagocytes nature: mechanisms and functions. Biochim Biophys Acta 1986;853:65-89.

12 Segal AW, West I, Wientjes F, Nugent JH, Chavan AJ, Haley $\mathrm{B}$, et al. Cytochrome b-245 is a flavocytochrome containing FAD and the NADPH-binding site of the microbicidal oxidase of phagocytes. Biochem $\mathcal{F} 1992 ; 284$ 781-8. 
13 Cross AR, Jones TG, Harper AM, Segal AW. Oxidationreduction properties of the cytochrome $b$ found in the plasma-membrane fraction of human neutrophils: a possible oxidase in the respiratory burst. Biochem $₹ 1981$; 194:599-606.

14 Rotrosen D, Yeung CL, Leto TL, Malech HL, Kwong CH. Cytochrome b558: the flavin-binding component of the phagocyte NADPH oxidase. Science 1992;256: the phagocy

15 Numoi H, Rotrosen D, Gallin JI, Malech L. Two forms of autosomal chronic granulomatous disease are deficient in distinct neutrophil cytosol factors. Science 1988,242:1298-301.

16 Lomax KJ, Leto TL, Nunoi H, Gallin JI, Malech HL. Recombinant 47-kilodalton cytosol factor restores NADPH oxidase in chronic granulomatous disease. Science 1989;245:409-12.

17 Leto TL, Lomax KJ, Volpp BD, Nunoi H, Sechler MG, Nauseef WM, et al. Cloning of a $67 \mathrm{KDa}$ neutrophil cytosolic oxidase factor and its similarity to a noncatalytic region of p60. c-src Science 1990;248:727-30.

18 Abo A, Pick E, Hall A, Toty N, Teahan CG, Segal AW. Activation of the NADPH oxidase involves the small GTP-binding protein 21 racl. Nature 1991;353:668-70.

19 Levy R, Malech HL, Rotrosen D. Production of myeloid cell cytosols functionally and immunochemically deficient in the $47 \mathrm{KDa}$ or $67 \mathrm{KDa}$ NADPH oxidase cytosolic factors. Biochem Biophys Res Commun 1990;170: lic factors.

20 Levy R, Rotrosen D, Nagauker O, Leto TL, Malech HL. Induction of the respiratory burst in HL-60 cells: correlation and protein expression. F Immunol 1990;145: 2595-601

21 Gilman G, Rall TW, Nies AS, Taylor P, eds. Goodman and Gilman's pharmacological basis of therapeutics. 8th ed. New York: Pergamon, 1991, 1313-19, 1322-4.

22 Freischlag JA, Colburn MD, Quinones-Baldrich WJ, Moore WS. Heparin, urokinase, and ancrod alter neutrophil function. $\mathcal{F}$ Vasc Surg 1992;16:565-74.
23 Burke SE, Wright CD, Potoczak RE, Boucher DM, Dodd GD, Taylor DG, et al. Reduction of canine myocardial infarct size by CI-959, an inhibitor of inflammatory cell activation. $\mathcal{F}$ Cardiovasc Pharmacol 1992;20: 619-29.

24 Willerson JT, Buja LM. Protection of the myocardium during myocardial infarction: pharmacologic protection during myocardial infarction: pharmacologic protection during

25 Ranjadayalain K, Umachandran V, Davies SW, Syndercombe-Court D, Gutteridge $\mathrm{CN}$, Timmis $\mathrm{AD}$. Thrombolytic treatment in acute myocardial infarction: neutrophil activation, peripheral leucocyte responses, and myocardial injury. Br Heart $\mathcal{f} 1991 ; 66: 10-4$.

26 Muir AL, Bell D. The role of the neutrophil in acute myocardial infarction. Health Bull (Edinb) 1989;47: 207-14.

27 Bell D, Jackson M, Nicoll J, Miller A, Dawes J, Muir AL. Inflammatory response, neutrophil activation, and free radical production after acute myocardial infarction: effect of thrombolytic treatment. $B r$ Hear $f$ 1990;63: 82-7.

28 Goldman G, Welbourn W, Paterson IS, Fracs MB, Klavsner JM, Lesner $\mathrm{K}$, et al. Ischemia-induced neutrophil activation and diapedesis is lipoxygenase dependent. Surgery 1990;107:428-33.

29 Cambria RA, Anderson RJ, Dikdan G, Techan EP, Hernandez-Maldonado JJ, Hobson RW. Leukocyte activation in ischemia-reperfusion injury of skeletal muscle. vation in ischemia-reperfusi

$30 \mathrm{Odeh} M$. The role of reperfusion-induced injury in the pathogenesis of the crush syndrome. $N$ Engl $f \mathrm{Med}$

31 Parini MI, Tringles MS, Tauber AI. Identification of distinct activation pathways of the human neutrophil NADPH oxidase. F Immunol 1986;137:2925-9.

32 Tarsi-Tsuk D, Levy R. Stimulation of oxidative burst in human monocytes by lipoteichoic acid: involvement of phospholipase $A_{2}$. F Immunol 1990;144:2665-70. 